\title{
Palladium(II) Complex of the 5-Hydroxypyridine-2-carbaldehyde N(4)-ethylthiosemicarbazone: Synthesis and Characterization
}

\author{
Paras Nath Yadav ${ }^{*}$, Laxman Bhattrai and Pramod K. Mehta \\ Central Department of Chemistry.Tribhuvan University.Kirtipur, Kathmandu, Nepal \\ E-mail: paras_yadav2002@yahyoo.com
}

\begin{abstract}
The novel complex of 5-hydroxypyridine-2-carbaldehyde N(4)-ethylthiosemicarbazone (HPyEt) with plalladium(II) have been prepared and characterized by elemental analysis, IR, ${ }^{I} H$-NMR, UV-visible spectroscopy and mass spectrometry $(F A B)$. Coordination of the anionic thiosemicarbazone ligand is via the pyridyl nitrogen, imine nitrogen and thiolato sulfur atoms and the fourth coordination site being occupied by chloride ion in square planar geometry.
\end{abstract}

Keywords: Hydroxypyridine; thiosemicarbazone; palladium complex.

\section{Introduction}

Thiosemicarbazones are very versatile ligands. They can coordinate to metals as neutral molecules or, after deprotonation, as anionic ligands, and can adopt a variety of different coordination modes ${ }^{1}$. Their antipathogenic and other biological activities in vitro depend on the $\mathrm{N}(4)$ substituent(s) ${ }^{2}$; the in vivo activity of those that are most active in vitro has been limited by their poor solubility in water. One agent of this series, 5- Hydroxy-2- carbaldehydethiosemicarbazone (5-HP), has been tested clinically and has shown carcinostatic potency in man. 5- Hydroxy-2- carbaldehydethiosemicarbazone (5-HP) is highly active intraperitioneally against leukemia L-1210, Ehrlich ascites carcinoma, and lymphoma L-5178 Y over a broad dose range ${ }^{3}$. The chemistry of the thiosemicarbazone has been an extremely active area of research primarily because of the beneficial biological (viz. antiviral, antibacterial, antitumor etc.) activities. The chelate palladium complex with salicylaldehyde $\mathrm{N}(4)$-ethyl thiosemicarbazone in which ligand is bound to the metal in an $\mathrm{O}, \mathrm{N}, \mathrm{S}$-tridentate coordination mode forming one six and one fivemembered chelating ring and synthesis and crystal structure of a palladium with salicylaldehyde $\mathrm{N}(4)$ hexamethyleneiminylthiosemicarbazone has been reported ${ }^{4,5}$.

In earlier work, we investigated the palladium(II) Complexes of N(4)-ethylthiosemicarbazone of 3Hydroxypyridine-2-carboxaldehyde and X-ray crystal structure has been solved ${ }^{6}$.

\section{Experimental Methods}

\section{Materials}

4-Ethyl-3-thiosemicarbazide and 5-hydroxy-2-methyl pyridine were commercially available from Aldrich. Palladium chloride was purchased from BDH laboratory reagent Pvt. Limited, Mumbai while lithium chloride from Loba Chemie Pvt. Ltd., Mumbai. Activated $\mathrm{MnO}_{2}$ was prepared by heating $\mathrm{MnCO}_{3}$ at $300{ }^{\circ} \mathrm{C}$ for $12 \mathrm{hr}$. Gravity column chromatography separation were carried out using 60-120 mesh silica gels (Qualigenes Fine Chemicals). Thin layer chromatography plates 60 GF 2540.2 mm, E.MerckDarmastadt, Germany were used for TLC to check the purity of the product. All the solvents

\section{"Corresponding author}


were purchased from Merck, Glaxo, BDH, Qualigens, and Ranbaxy chemical companies and used without further purification.

\section{Measurements}

Electronic spectra in DMF ( $5 \times 10^{-5} \mathrm{~mol} / \mathrm{L}$ ) were recorded on Perkin Elmer Lambda 40 UV/VIS spectrometer at Drugs Administration Centre, Bijulibazar, Babarrmahal, Kathmandu. Elemental analysis $(\mathrm{C}, \mathrm{H}, \mathrm{N}), \mathrm{FAB}$ mass spectra measurements and NMR ( $\mathrm{d}_{6}$-DMSO) spectra of complex were obtained from Central Drug Research Institute (CDRI), Lucknow, India. 2D-NMR of thiosemicarbazone was recorded in $\mathrm{d}_{6}$-DMSO at RT on Nippon Denshi JEOL FT-500 NMR Spectrometer in Japan. The FAB mass spectra was recorded on a Jeol SX 102/Da-600 mass spectrometer/Data system using argon/xenon $(60 \mathrm{kV}, 10 \mathrm{mAO})$ as the FAB gas at CDRI. The accelerating voltage was $10 \mathrm{kV}$ and spectrum was recorded at room temperature. m-Nitrobenzyl alcohol was used as the matrix. IR spectra were recorded on Nexus FTIR spectrometer (Thermo Nicolet) at University of Padova (KBr). Analysis of palladium and chlorine were done by gravimetric and potentiometric techniques, respectively at Central Department of Chemistry, Tribhuvan university, kirtipur, Kathmandu.

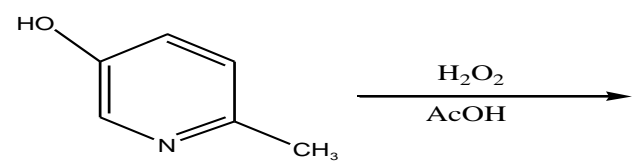<smiles>Cc1ccc(O)c[n+]1[O-]</smiles>
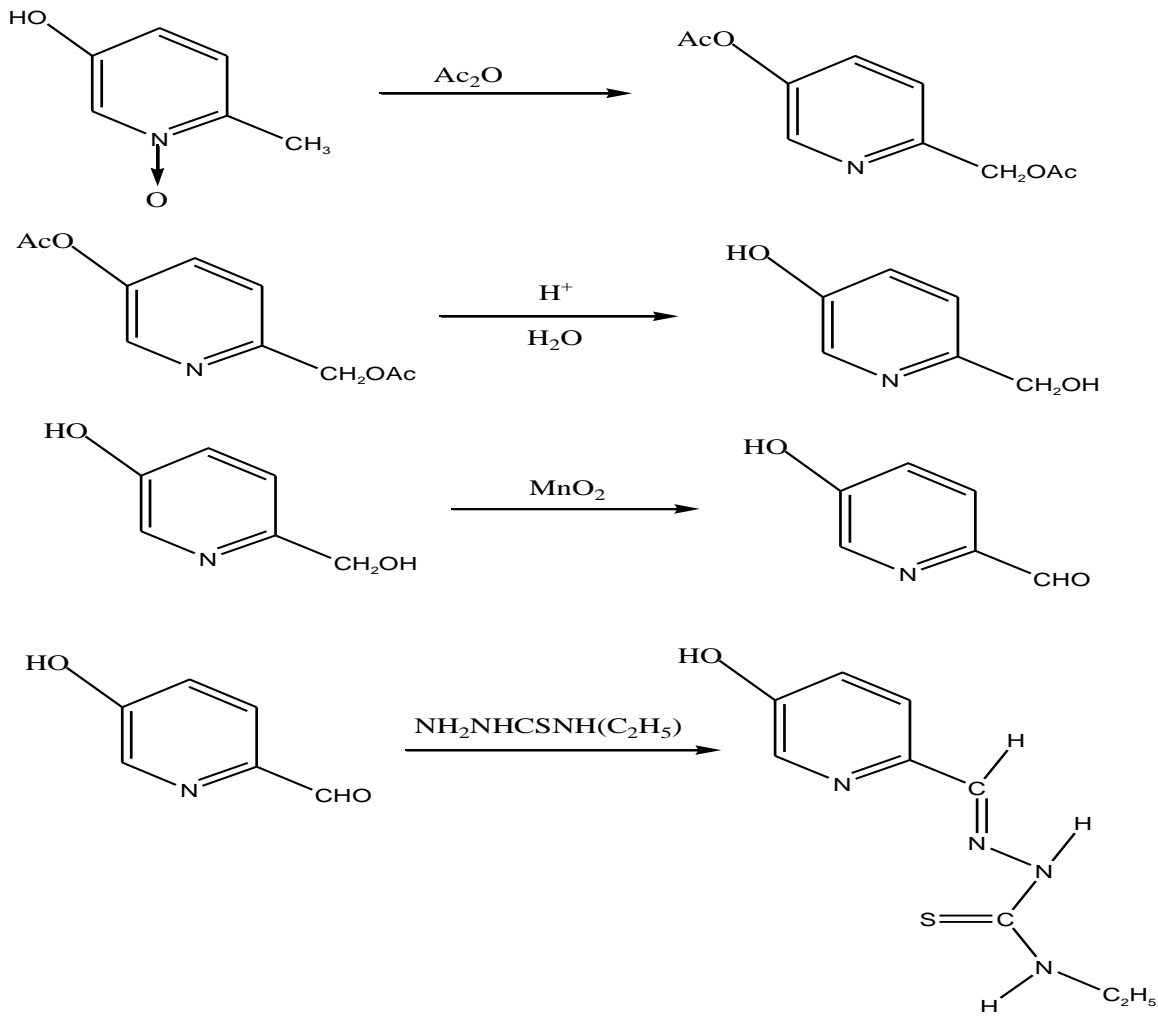

Scheme I. Synthesis of 5-Hydroxypyridine-2-carbaldehyde N(4)-ethylthiosemicarbazone. 


\section{Synthesis of 5-Hydroxypyridine-2-carbaldehyde N-ethylthiosemicarbazone}

5-Hydroxypyridine-2-carbaldehyde $\mathrm{N}(4)$-ethylthiosemicarbazone was prepared by the method described by E. J. Blanz, Jr. et. $\mathrm{al}^{7}\left(\right.$ scheme I) and characterized by elemental analysis IR, UV-Vis, ${ }^{1} \mathrm{H}$ and 2D-NMR spectra. Yield: $84 \%$. Pale cream.M.P. $205^{\circ}$ C. UV/VIS (DMF, $\left.\mathrm{cm}^{-1}\right): 30,487 \mathrm{~b} *(1.96)$ IR: $3297 \mathrm{~m}\{v(\mathrm{OH})\} ; 3257 \mathrm{~m}\{v \mathrm{~N}(4) \mathrm{H}\} ; 3208 \mathrm{~m}\{v \mathrm{~N}(3) \mathrm{H}\} ; 1592 \mathrm{w}\{v(\mathrm{C}=\mathrm{N})\} ; 1557 \mathrm{~s}, 1532 \mathrm{~m}\{\delta\{\mathrm{N}(4) \mathrm{H}\}+$ $\delta\{\mathrm{N}(3) \mathrm{H}\} ; 1489 \mathrm{~s}, 1428 \mathrm{~m}$ (Ring breath); 1225s $\{v(\mathrm{C}-\mathrm{O})\} ; 1101 \mathrm{~s}\{v(\mathrm{~N}-\mathrm{N})\} ; 801 \mathrm{~m}\{\mathrm{v}(\mathrm{C}=\mathrm{S})\} .{ }^{1} \mathrm{H}-\mathrm{NMR} 1$ : $11.44\{\mathrm{~N}(3) \mathrm{H}\} ; 10.36\{\mathrm{C}(5) \mathrm{OH}\} ; 8.56\{\mathrm{~N}(4) \mathrm{H}\} ; 8.09\{\mathrm{C}(6) \mathrm{H}, \mathrm{C}(7) \mathrm{H}\} ; 8.00\{\mathrm{C}(4) \mathrm{H}\} ; 7.20\{\mathrm{C}(3) \mathrm{H}\}$; 1.12, $3.56\left\{\mathrm{~N}(4) \mathrm{C}_{2} \mathrm{H}_{5}\right\} ;{ }^{13} \mathrm{C}-\mathrm{NMR}: 176.69(\mathrm{C}=\mathrm{S}) ; 154.46 \mathrm{C}(\mathrm{OH}) ; 144.48 \mathrm{C}(2) ; 1142.45 \mathrm{C}(4) ; 137.32$ $\mathrm{C}(6) ; 122.73 \mathrm{C}(3) ; 121.34 \mathrm{C}(7) ; 38.30,14.55\left\{\mathrm{~N}(4) \mathrm{C}_{2} \mathrm{H}_{5}\right\}$. Anal.calc. for $\mathrm{C}_{9} \mathrm{H}_{12} \mathrm{~N}_{4} \mathrm{OS}: \mathrm{C} 48.20, \mathrm{H}$ 5.39, $\mathrm{N}$ 24.98, ; found: C 47.86, H 5.17, N 24.29.

*b $=$ Broad; $\mathrm{m}=$ Medium; $\mathrm{w}=$ Weak

Synthesis of chloro(5-hydroxypyridine-2-carbaldehyde N(4)-ethylthiosemicarbazonato) palladium(II)

To lithium tetrachloropalladate $(1.2 \mathrm{mmol})$, prepared in situ from $\mathrm{PdCl}_{2}$ and $\mathrm{LiCl}$, in $\mathrm{MeOH}(9 \mathrm{ml})$ was added a solution of ligand (1mmol) in $\mathrm{MeOH}(8 \mathrm{ml})$. The mixture was stirred for $24 \mathrm{~h}$ at room temperature, and then left standing in a refrigerator for $24 \mathrm{~h}$. The resulting orange precipitate was filtered off, washed with cold $\mathrm{MeOH}$ and then with ether and dried at $50{ }^{\circ} \mathrm{C}$ for $12 \mathrm{hr}$ and then at $95{ }^{\circ} \mathrm{C}$ for $1.5 \mathrm{hr}$. Yield: $80 \%$.Orange yellow. M.P. $241^{\circ} \mathrm{C}$. UV/VIS (DMF, $\mathrm{cm}^{-1}$ ): 31,446s ( ), 26315b ( ), 21,276b ( ). IR: $3032 \mathrm{w}[\{v(\mathrm{OH})+v\{\mathrm{~N}(4) \mathrm{H}\}] ; 1600 \mathrm{sb} ;\{v(\mathrm{C}=\mathrm{N})\} ; 1600 \mathrm{sb}, 1567 \mathrm{~s}\{\delta\{\mathrm{N}(4) \mathrm{H}\}+\delta\{\mathrm{N}(3) \mathrm{H}\} ; 1520 \mathrm{~m}, 1489 \mathrm{w}$, $1457 \mathrm{~m}$ (Ring breath); 1210s $\{v(\mathrm{C}-\mathrm{O})\} ; 1152 \mathrm{w} \quad\{\mathrm{v}(\mathrm{N}-\mathrm{N})\} ; \quad 706 \mathrm{~m} \quad\{\mathrm{v}(\mathrm{C}=\mathrm{S})\} . \quad{ }^{1} \mathrm{H}-\mathrm{NMR} 1$ : $8.12\{\mathrm{~N}(4) \mathrm{H}\} ; 7.88\{\mathrm{C}(6) \mathrm{H}\} ; 8.01\{\mathrm{C}(7) \mathrm{H} \quad\} ; 7.62\{\mathrm{C}(4) \mathrm{H}\} ; 7.48\{\mathrm{C}(3) \mathrm{H}\} ; \quad 3.23, \quad 1.07\left\{\mathrm{~N}(4) \mathrm{C}_{2} \mathrm{H}_{5}\right\}$.Anal. calc.for $\mathrm{C}_{9} \mathrm{H}_{11} \mathrm{ClN}_{4} \mathrm{OPdS} \cdot \mathrm{H}_{2} \mathrm{O}$ : C 28.18; $\mathrm{H} 3.39 ; \mathrm{Cl} 9.26 ; \mathrm{N} 14.61 ; \mathrm{Pd} 27.77$; found: $\mathrm{C} 27.79 ; \mathrm{H} 3.45 ; \mathrm{Cl}$ 9.80; N14.21; Pd 28.34;

\section{Results and discussion}

\section{IR Spectroscopy}

The highest frequency band at $3297 \mathrm{~cm}^{-1}$ for thiosemicarbazone was assigned to $v(\mathrm{OH})$ stretch. The frequency at $3257 \mathrm{~cm}^{-1}$ was assigned to stretches of terminal $\mathrm{N}(4) \mathrm{H}$ and the bands in $3208 \mathrm{~cm}^{-1}$ range was assigned to stretch of $\mathrm{N}(3) \mathrm{H}$. In the spectra of ligand, no $v(\mathrm{SH})$ band in the $2600-2500 \mathrm{~cm}^{-1}$ range was observed, in agreement with the presence of thione form ${ }^{6}$.

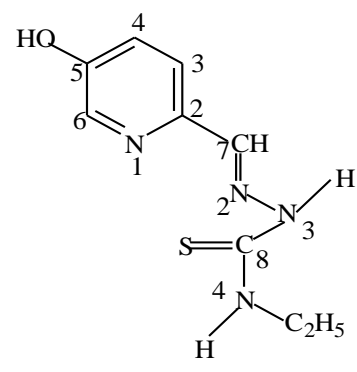

Figure 1.5-Hydroxypyridine-2-carbaldehyde N4)-ethylthiosemicarbazone.

The strong band at $1592-1600 \mathrm{~cm}^{-1}$ in thiosemicarbazone attributed to $v(\mathrm{C}=\mathrm{N})$ is shifted to higher frequency in the complex coupled with $\delta\{\mathrm{N}(4) \mathrm{H}\}$ and $\delta\{\mathrm{N}(3) \mathrm{H}\}$ to give broad band. Coordination of azomethine nitrogen of the deprotonated ligand is further supported by shift of $v(\mathrm{~N}-\mathrm{N})$ band to higher energy in the IR spectra of the complex compared to that in the ligand and absence of $v \mathrm{~N}(3) \mathrm{H}$ stretch in the high frequency region. The breathing motion of the pyridine ring was shifted to a higher frequency 
upon complexation and it was consistent with pyridine ring nitrogen coordination. The characteristic $v(\mathrm{C}$ O) stretch at $1225 \mathrm{~cm}^{-1}$ in the free thiosemicarbazone has been shifted insignificantly to lower frequency in the complex which clearly indicated that carbonyl oxygen has not been involved in coordination. Coordination of carbonyl oxygen leads to decreasing in $v(\mathrm{C}-\mathrm{O})$ stretch by $70-80 \mathrm{~cm}^{-1}$. Small shift in $v(\mathrm{C}-$ $\mathrm{O})$ stretch in the complex compare to that in free ligand was due to different strength of hydrogen bond in two. The $v(C=S)$ vibration in the free ligand at $801 \mathrm{~cm}^{-1}$ appears at lower frequency with reduced intensity in the complex at $706 \mathrm{~cm}^{-1}$, suggesting coordination of sulfur in the deprotonated thiolate form,

\section{NMR spectroscopy}

Peak assignments are based on 2D-NMR data $\left({ }^{1} \mathrm{H},{ }^{1} \mathrm{H}-\mathrm{COSY} ;{ }^{1} \mathrm{H},{ }^{13} \mathrm{C}-\mathrm{HMQC} ;{ }^{1} \mathrm{H},{ }^{13} \mathrm{C}-\mathrm{HMBC}\right)$. For free thiosemicarbazone, $\mathrm{N}(3) \mathrm{H}$ was found down field at $11.44 \mathrm{ppm}$ due to its hydrogen bonding to the pyridine nitrogen. Existence of single strong resonance at such a down field for $\mathrm{N}(3) \mathrm{H}$ reveals that it predominantly exist in the form of $\mathrm{Z}$-isomer. Free ligand did not show any peak attributed to S-H proton indicating that it exist in thione form. The broad peak in the $10.39 \mathrm{ppm}$ region was identified as $\mathrm{C}(5) \mathrm{OH}$ signal and it was not detected in the complex may be because of excessive hydrogen bonding or exchange of $-\mathrm{OH}$ proton with the water molecule ${ }^{6,11,12}$.

In the ${ }^{1} \mathrm{H}-\mathrm{NMR}$ spectra of the complex, $\mathrm{C}(6) \mathrm{H}$ in the free ligand $(8.09 \mathrm{ppm})$ was shifted up field in the complex $(7.88 \mathrm{ppm})$ upon coordination, in accord with an increased electron density at this site in the complex due to $\pi$-back bonding from $\mathrm{Pd}(\mathrm{II})^{11}$. Absence of the $\mathrm{N}(3) \mathrm{H}$ signal in the complex, implies that anionic ligand was involved in coordination ${ }^{9,11}$.

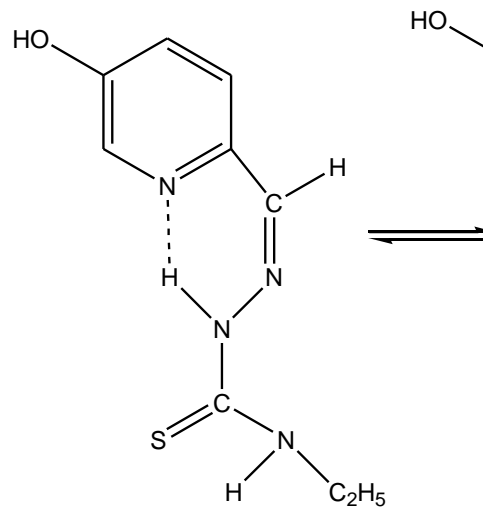

Z-Isomer

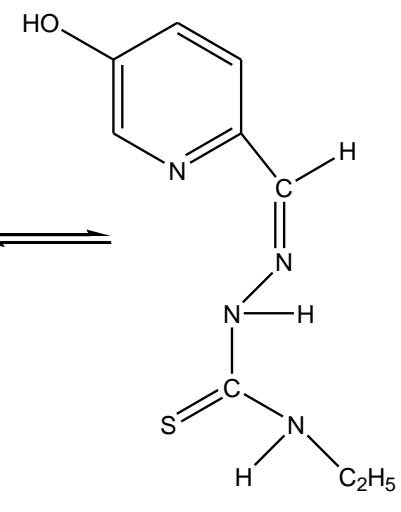

E-Isomer

Figure 2.Isomers of 5-Hydroxy-2-carbaldehyde N(4)-ethylthiosemicarbazone.

On coordination of the sulphur and imine nitrogen atoms the electron density would be expected to be lost from the $\mathrm{H}-\mathrm{C}=\mathrm{N}$ function, as has been observed for many complexes of thiosemicarbazones. However, $\pi$-back bonding from the palladium(II) to the thiolate and imine functions occurs causing an up field shift. The shift of $\mathrm{N}(4) \mathrm{C}_{2} \mathrm{H}_{5}$ proton resonance were not significant as the aldehyde hydrogen because of their greater distance from the coordinating thion sulphur ${ }^{13}$.

${ }^{1} \mathrm{H}-\mathrm{NMR}$ signals in the complex were essentially shifted upfield compare to that of free thiosemicarbazone and the affected proton resonance were $\mathrm{C}(6) \mathrm{H}, \mathrm{C}(7) \mathrm{H}$ and $\mathrm{S}=\mathrm{C}-\mathrm{N}(4) \mathrm{H}$. These upfield shifts support coordination of the pyridinyl nitrogen, azomethine nitrogen and thionyl sulphur to $\mathrm{Pd}(\mathrm{II})$ forming two five membered chelate rings around $\mathrm{Pd}(\mathrm{II})$ centre which contribute to the stability of the complex a structural motive that seems to be stable both in the solid state and in DMSO solution ${ }^{11,12}$. 


\section{Electronic Spectroscopy}

$\mathrm{N}(4)$-Ethylthiosemicarbazone have broad band at $30,487 \mathrm{sb} \mathrm{cm}^{-1}(1.96)^{*}$ associated with the $\mathrm{n} \rightarrow \pi^{*}$ of the pyridine ring and TSC moiety (imine, thiomide) transition which has shifted at $31,446 \mathrm{~s} \mathrm{~cm}^{-1}$ (1.10) in the complex. In the visible region of square planar complexes of Pd(II), three spin allowed ${ }^{1} \mathrm{~A}_{1 \mathrm{~g}} \rightarrow{ }^{1} \mathrm{~A}_{2 \mathrm{~g}}$, $<{ }^{1} \mathrm{~A}_{1 \mathrm{~g}} \rightarrow{ }^{1} \mathrm{~B}_{1 \mathrm{~g}},\left\langle{ }^{1} \mathrm{~A}_{1 \mathrm{~g}} \rightarrow{ }^{1} \mathrm{E}_{1 \mathrm{~g}}\right.$, and three spin forbidden singlet-triplet $\mathrm{d}$-d transitions from the three lower lying $d$ levels to the empty $d_{x}{ }^{2}-y^{2}$ orbitals are predicted. However, strong charge transfer transition for $[\mathrm{Pd}(\mathrm{PyEt}) \mathrm{Cl}] \cdot \mathrm{H}_{2} \mathrm{O}$ interfere and prevent the observation of all the expected bands. The band at $21,276 \mathrm{sb}$ $\mathrm{cm}^{-1}(0.37)$ was assignable to a combination of $\mathrm{S} \rightarrow \mathrm{Pd}(\mathrm{II})$ charge transfer, $\mathrm{N}$ (pyridinyl) $\rightarrow \mathrm{Pd}$ (II) charge transfer and $\mathrm{Pd}(\mathrm{II}) \mathrm{d} \rightarrow \mathrm{dbands}$. This band is also associated with spin-forbidden singlet-triplet transition which could have gained intensity through spin-orbit coupling. The band at $26,315 \mathrm{sh} \mathrm{cm}^{-1}(0.82)$ was assignable to a combination of ligand-metal $(\mathrm{L} \rightarrow \mathrm{M})$ and metal-ligand $(\mathrm{M} \rightarrow \mathrm{L})$ charge transfer and d-d bands. A comparison of these bands with bands of free ligands revealed that there is decrease in intensity and increase in the frequency that is attributed to coordination of ligand ${ }^{11,12,14,15}$.

$*()=$ Absorbance; $\mathrm{s}=$ Strong, $\mathrm{sb}=$ strong broad, $\mathrm{sh}=$ Shoulder, $\mathrm{b}=$ Broad.

\section{Mass spectrometry}

The FAB mass spectrum of complex was recorded using m-nitrobenzyl alcohol (NBA) as the matrix. The spectrum of Pd(II) complex showed a number of informative fragment ions of different intensity confirming its molecular weight. The molecular ion peak was observed as $[\mathrm{M}]^{+}(\mathrm{m} / \mathrm{z}=383)$ and the major fragmentation pathway involved the cleavage of thioamide group giving highest mass fragment at $\mathrm{m} / \mathrm{z} 369$ (a) correspond to removal of $-\mathrm{CH} 2$ fraction from $-\mathrm{N}(4) \mathrm{C}_{2} \mathrm{H}_{5}$. A peak at $\mathrm{m} / \mathrm{z} 109$ corresponds to the hydroxypicolinering fragment. The mass spectrum of the complex shows fragmentation patterns corresponding to succesive degradations of the molecule. A general splitting pathway followed by the complex is shown in scheme 2. The result presented here is interpreted in terms of simple bond cleavage and ligand losses ${ }^{16,17}$. A peak at $\mathrm{m} / z, 367$ corresponds to the fragment $\left[\mathrm{C}_{8} \mathrm{H}_{7} \mathrm{~N}_{4} \mathrm{OPdSCl} . \mathrm{H}_{2} \mathrm{O}\right.$ ] (b). Similarly, all the peaks at different $\mathrm{m} / \mathrm{z}$ are shown in the scheme II.

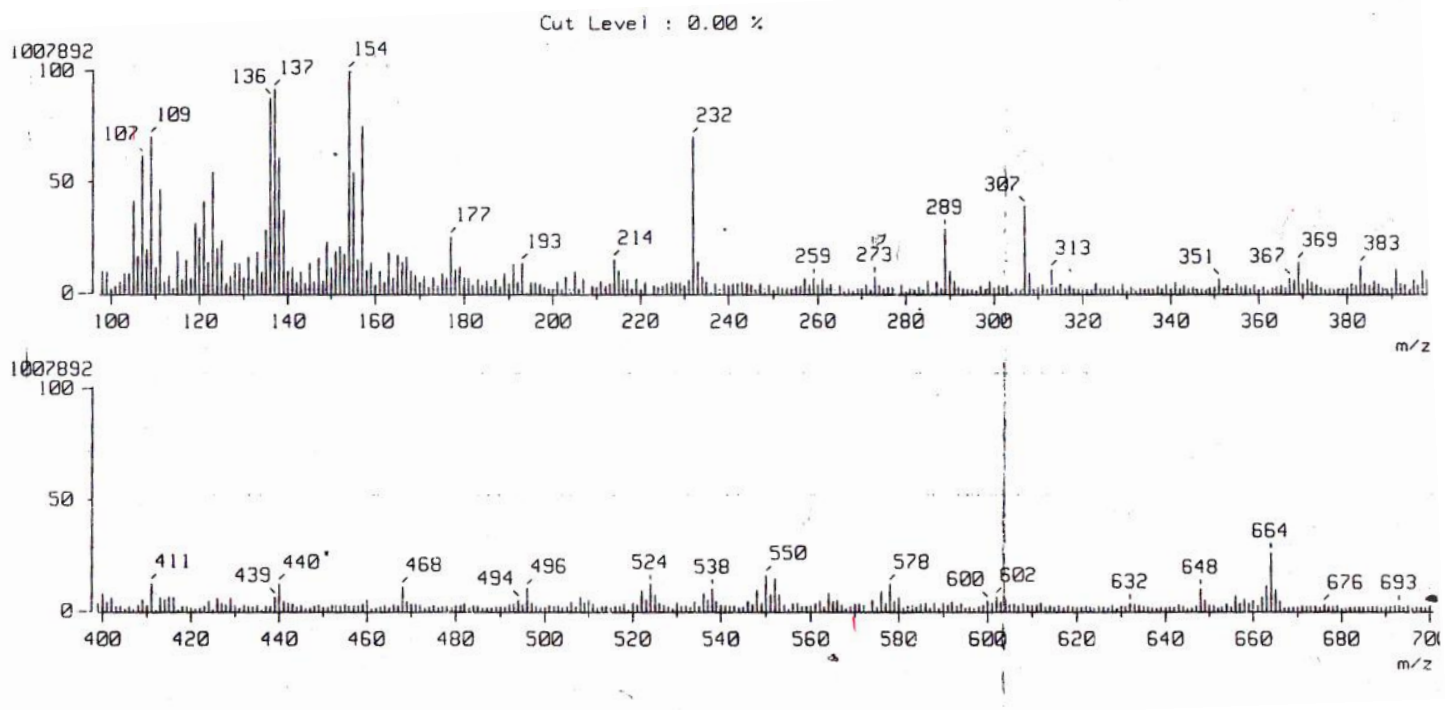

Fig. 3. Mass Spectra (FAB) of $[\mathrm{Pd}(\mathrm{PyEt}) \mathrm{Cl}] \cdot \mathrm{H}_{2} \mathrm{O}$. 
J. Nepal Chem. Soc., vol. 28, 2011

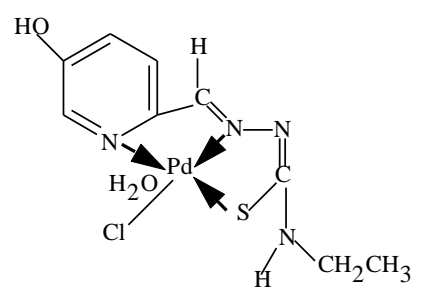

$\left[\mathrm{C}_{9} \mathrm{H}_{11} \mathrm{~N}_{4} \mathrm{OPdSCl} . \mathrm{H}_{2} \mathrm{O}\right]$

$\mathrm{m} / \mathrm{z}=383$

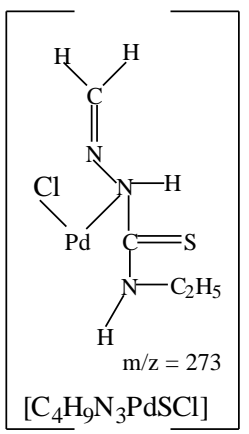

(e)

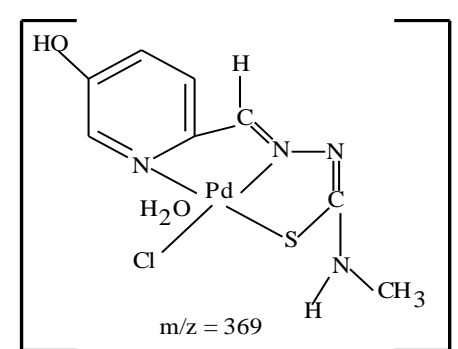

$\left[\mathrm{C}_{8} \mathrm{H}_{9} \mathrm{~N}_{4} \mathrm{OPdSCl} . \mathrm{H}_{2} \mathrm{O}\right]$

(a)

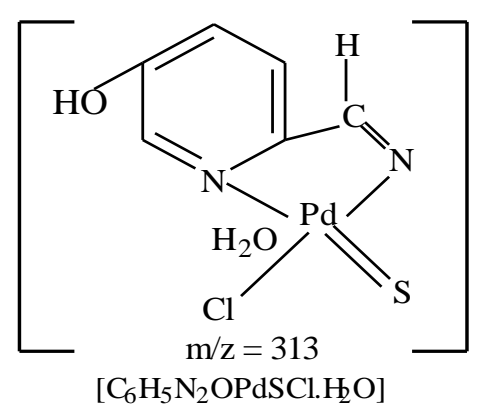

(d)

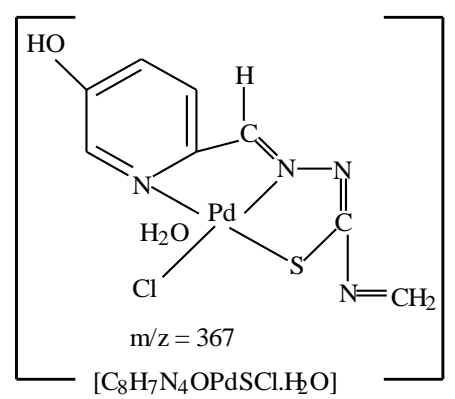

(b)

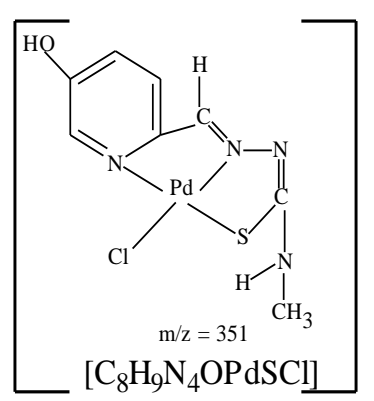

(c)

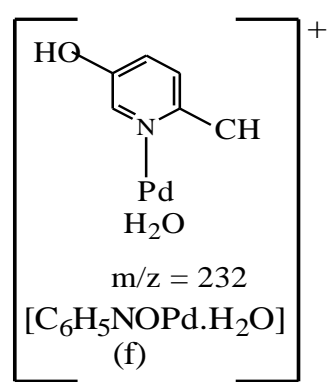

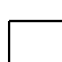

$\mathrm{HQ}$<smiles>Cc1ccc(C)nc1</smiles>

$\mathrm{m} / \mathrm{z}=109$

$\left[\mathrm{C}_{6} \mathrm{H}_{7} \mathrm{NO}\right]$

(j)

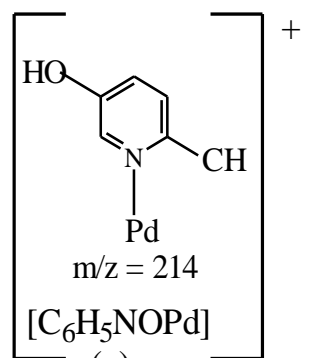

$\left[\mathrm{C}_{6} \mathrm{H}_{5} \mathrm{NOPd}\right]$

(g)
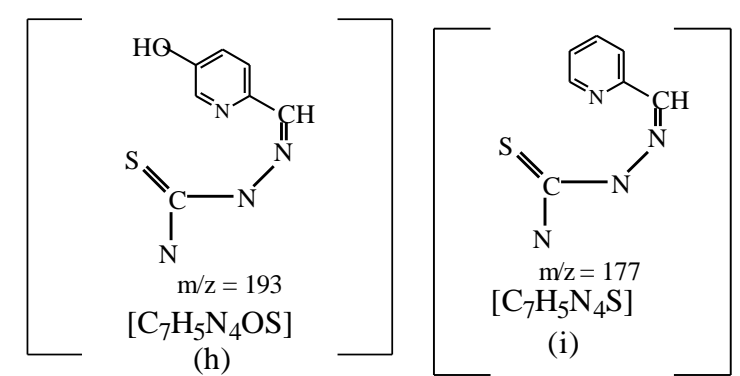

Scheme II. Proposed mass fragmentation pattern for complex $[\mathrm{Pd}(\mathrm{PyEt}) \mathrm{Cl}] . \mathrm{H}_{2} \mathrm{O}$. 


\section{Conclusions}

5-Hydroxypyridine-2-carbaldehyde N(4)-ethylthiosemicarbazone was prepared and characterized by elemental analysis, IR, UV-Vis, and 2D-NMR spectra. From the reaction between lithium tetrachloropalladate prepared in situ from $\mathrm{PdCl}_{2}$ and $\mathrm{LiCl}$ and 5-Hydroxy-2-carbaldehyde $\mathrm{N}(4)$ ethylthiosemicarbazone, complex of stoichiometry $1: 1$ and general formula $[\mathrm{Pd}(\mathrm{PyEt}) \mathrm{Cl}] \cdot \mathrm{H}_{2} \mathrm{O}$ was obtained. Palladium(II) complex $[\mathrm{Pd}(\mathrm{PyEt}) \mathrm{Cl}] \cdot \mathrm{H}_{2} \mathrm{O}$ characterized by elemental analysis IR, ${ }^{1} \mathrm{H}-\mathrm{NMR}$, UV-visible spectroscopy and mass spectrometry (FAB) confirmed the expected palladium cation coordination by a chloride anion and thiosemicarbazonato anion; co-ordinated by pyridyl nitrogen, azomethine nitrogen and thionylsulphur The ligand was coordinated as a tridentate shown by NMR and IR spectroscopy. The overall geometry of the complex was square planar, based on composition, coordination number and mode of coordination. Hydroxy group was found non deprotonated and not involving in coordination with $\mathrm{Pd}(\mathrm{II})$ in the complex.

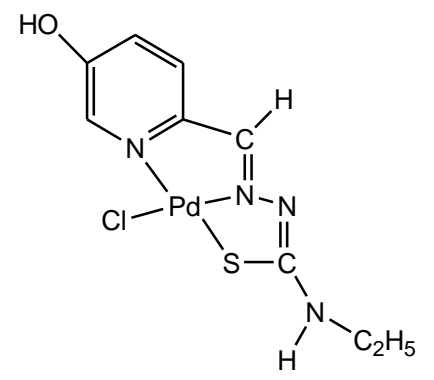

\section{Acknowledgements}

We gratefully acknowledge Nepal Academy of Science (NAST) for financial support and Central Drug Research Institute (CDRI), Lucknow, India for providing NMR, CHN analysis and mass spectra of compound. We express sincere thanks to Dr. R. A. Adhikari and University of Padova for IR spectra.

\section{References}

1. (a) E.S. R,per, Coord. Chem. Rev., 1985, 61, 115. (b) D.X. West, S.B. Padhye and P.B. Sonawane, Struct. Bonding (Berlin), 1991, 76, 4. (c) J.S. Casas and, M.S. Garcia-Tasende, J. Sordo, Coord. Chem. Rev., 2000, 209, 49.

2. (a) M.C. Miller, C.N. Stineman, J.R. Vance, D.X. West and I.H.Hall, Anticancer Res., 1998, 18, 4131,(b) I.H. Hall, B.J. Barnes, J.E. Rowell, K.A. Shaffer, S.E. Cho, D.X. West and A.M. Stark, Pharmazie, 2001, 56, 648.

3. (a) R. C. Deconti, B. R. Toftness, K. C. Agrawal, R. Tomchik, J.A.R. Mead, J. R. Bertino, A. C. Sartorelli and W. A. Creasey, Cancer Res., 1972, 32, 1455. (b) I. H. Krakoff, E. Etkubanas, C. Tan, K. Mayer, V. Bethune and J. H. Burchenal, Cancer Chemother. Rep. Part I, 1974, 58, 207212.

4. D.Kovola-Demertii, P. N. Yadav, M. A. Demertizs, J. P. Jasiski, F. J. Andreadaki and I. D. Kostas, Tetrahedron Lett., 2004, 45, 2923-2926. 
5. I. D. Kostas, G. A. Heropoulos, D.Kovola-Demertii, P. N. Yadav, J. P. Jasinski, M. A. Demertzis, F. J. Andreadaki, G.Vo-Thanh, A. Petit and A.Loupy, Tetrahedron Letters, 2006, 47, 4403-4407.

6. M. A. Demertzis, P. N. Yadav, and D.Kovala-Demertzi, Helvetica ChimicaActa, 2006, 89, 1959.

7. E. J. Blanz, Jr. and F. A. French, J. R. Doamaral and D. A. French, J. Med. Chem., 1970, 13, 1124.

8. M. C. Rodriguez-Arguelles, M. B. Ferrari, G. G. Fava, C. Pelizzi, P. Tarasconi, R. Albertini, P. P. Dall'Aglio, P. Lunghi and S. Pinelli, J. Inorg. Biochem., 1995, 58, 157-175.

9. D. Kovala-Demertzi, P. N. Yadav, J. Wiecek, S. Skoulika, T. Varadinova and M. A. Demertzis, J. Inorg. Biochem., 2006, 100, 1558-1567.

10. D. Kovola-Demertzi, P. N. Yadav, M. A. Demertzis and M. Coluccia, J. Inorg. Biochem., 2000, 78, 347.

11. D. Kovala-Demertzi, A. Alexandratros, A. Papageorgious, P. N. Yadav, P. Delezis and M. A. Demertzis, Polyhedron , 2008, 27, 2731-2738.

12. A. Castineiras, M.Gil, E. Bermejo and D. X. West, Polyhedron, 2001, 20, 449-454.

13. D. X. West, C. S. Carlson and K. J. Bouck and A. E. Liberta, Transition Metal Chemistry, 1991, 16, 271.

14. A.B.P. Lever, Inorganic Electronic Spectroscopy, 2nd ed., Elsevier, Amsterdam, 1984

15. P. N. Yadav, Mavroudis A. Demertzis, D.Kovala-Demertzi, S. Skoulika and D. X. West.InorganicaChimicaActa, 2003, 349, 30-36.

16. K. Husain, A.RooufBhat and A.Azam, Eur. J. Med. Chem., 2008, 43, 2016e, 2028.

17. K. Husain, M.Abid and A.Azam, Eur. J. Med. Chem., 2007, 42, 1300e, 1308. 